\title{
Diaphragmatic paralysis following cervical herpes zoster - a rarely recognized association
}

\author{
GAUTAM R SOPARKAR MD MRCP(UK) FRCPC \\ Department of Medicine, University of Saskatchewan, Saskatoon, Saskatchewan
}

GR SOPARKAR. Diaphragmatic paralysis following cervical herpes zoster - a rarely recognized association. Can Respir J 1995;2(2):131-134.

An 83-year-old woman was found to have a paralyzed hemidiaphragm less than three weeks after developing cervical herpes zoster. The diaphragm was radiographically normal the day before the skin rash appeared. The relatively short time frame and lack of evidence to indicate other etiologies suggests herpes zoster as the likely cause of the paralysis. Diaphragmatic paralysis following cervical herpes zoster is probably underrecognized and the association between the two conditions can be easily missed, especially if the interval between their detection is long.

Key Words: Diaphragmatic paralysis, Herpes zoster

\section{Paralysie du diaphragme suivant un zona cervical - une association rarement reconnue}

RESUMÉ: Un diagnostic de paralysie de l'hémidiaphragme a été porté chez une femme de 83 ans à la suite d'un zona cervical s'étant développé chez cette dernière moins de trois semaines auparavant. La radiographie du diaphragme était normale le jour précédant I'irruption cutanée. Le laps de temps assez court et l'absence d'autres étiologies laissent penser yue le zona est vraisemblablement responsable de la paralysie du diaphragme. La paralysie du diaphragme suivant un zona est probablement sous-diagnostiquée et l'association entre les deux conditions peut facilement passer inaperçue, en particulier si l'intervalle de temps entre la détection du zonat cl celle de la paralysie est long.
$\mathrm{D}$ IAPHRAGMATIC PARAI YSIS FOLLOOWING CERVICAL HER pes zoster has rarcly been reported. A further case is described here, not only on account of its rarity, but because, unlike most previous reports, the full sequence of events was documented over a very short time.

\section{CASE PRESENTATION}

An 83-year-old woman was admitted to hospital with complaints of chest pain and dyspnea (day 1). She hact at history of ischemic heart disease, congestive heart failure, osteoarthritis, hypothyroidism (on thyroxine replacement) and polymyalgia rheumatica (for which she was taking prednisone). She was dyspneic on walking one block and had some associated orthopnea. The chest pain was of the "pressure' type, usually brought on by cxercisc and relieved by nitroglycerin. Coronary ischemia with heart failure was considered initially. However, on physical examination, there was no evidence of heart failure, examination of the chest was unremarkable and an electrocardiogram showed no acute changes. A chest radiograph on day 2 was normal (Figure 1 ).

On day 2 , she complained of pain in the region of the left shoulder and neck and applied a hot pad to the area. The next

Correspondence: Dr GR Soparkar, Department of Medicine. Ruyat University Hospital, 103 Hospital Drive. Saskutoon, Saskatchewan S7N OW8. Telephone (306) 966-7947. Fax (306) 966-8021 


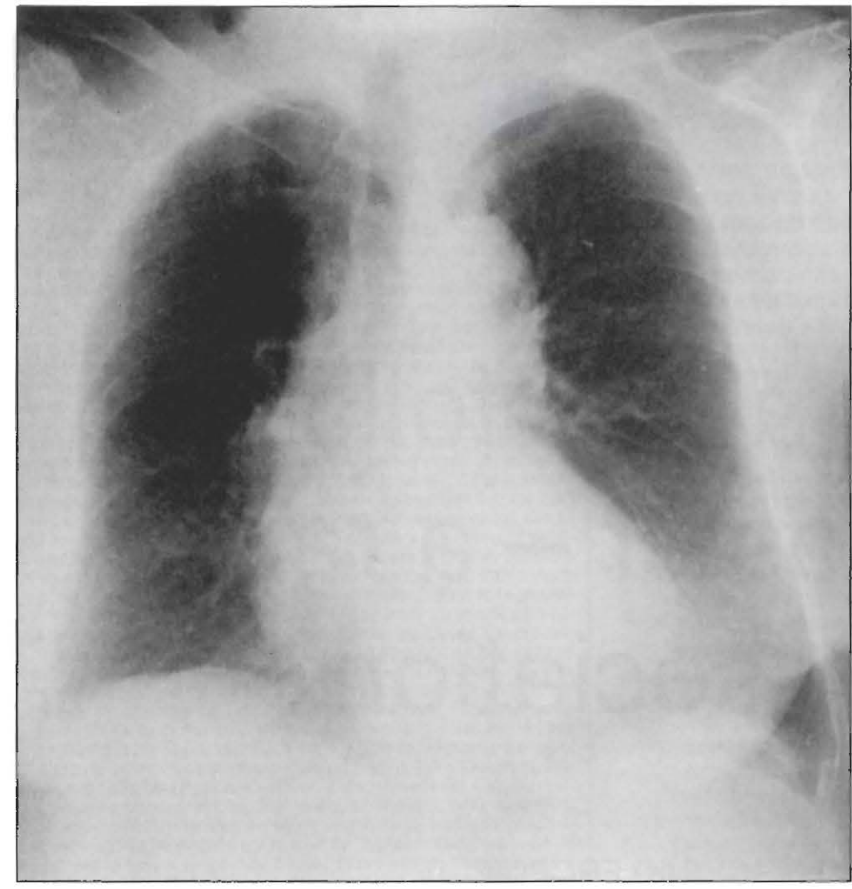

Figure 1) Chest rudiograph of patient on des 2 following admission

day (day 3), she was found to have local erythema and a few blisters, which were initially attributed to a burn from the hot pad. However, when more blisters appeared and were localized to the left cervical and upper thoracic dermatomes, at diagnosis of herpes zoster was made. The rash progressed to crusting over a few days.

In retrospect, the shoulder and neck pain was probably due to herpes zoster. The chest pain at presentation was probably cardiac in origin, although zoster of the upper left chest may have been contributory. The cause of the dyspneat at presentation was not definitely established, but it could have been due to heart failure, which was not clinically manifest at rest.

A few days after the rash appeared, she noticed worsening of dyspnea, especially on lying down. A repeat chest radiograph (day 20) showed that the left hemidiaphragm was elevated with no tung parenchymal or mediastinal abnormality (Figure 2). Fluoroscopy showed paradoxical movement of the left hemidiaphragm and a positive "sniff" test, confirming hemidiaphragmatic paralysis. Spirometry showed forced vital capacity (FVC) to be $79 \%$ of predicted and forced expiratory volume in I $\mathrm{s}\left(\mathrm{FEV}_{1}\right)$ to be $88 \%$ of predicted. Lung volumes could not be measured due to dyspnea. Pulse oximetry showed no hypoxemia in the sitting or supine positions. The maximal inspiratory airway pressure (PImax) was found to be low at $28 \mathrm{~cm} \mathrm{H}_{2} \mathrm{O}$, even for a woman of her age (1).

The patient was advised to sleep in a propped-up position to minimize dyspnea. At discharge (day 32), there was no improvenent in PImax, though the patient reported some subjective improvement in shortness of breath. Three months after it was first detected, the left hemidiaphragm was still elevated on chest radiography.

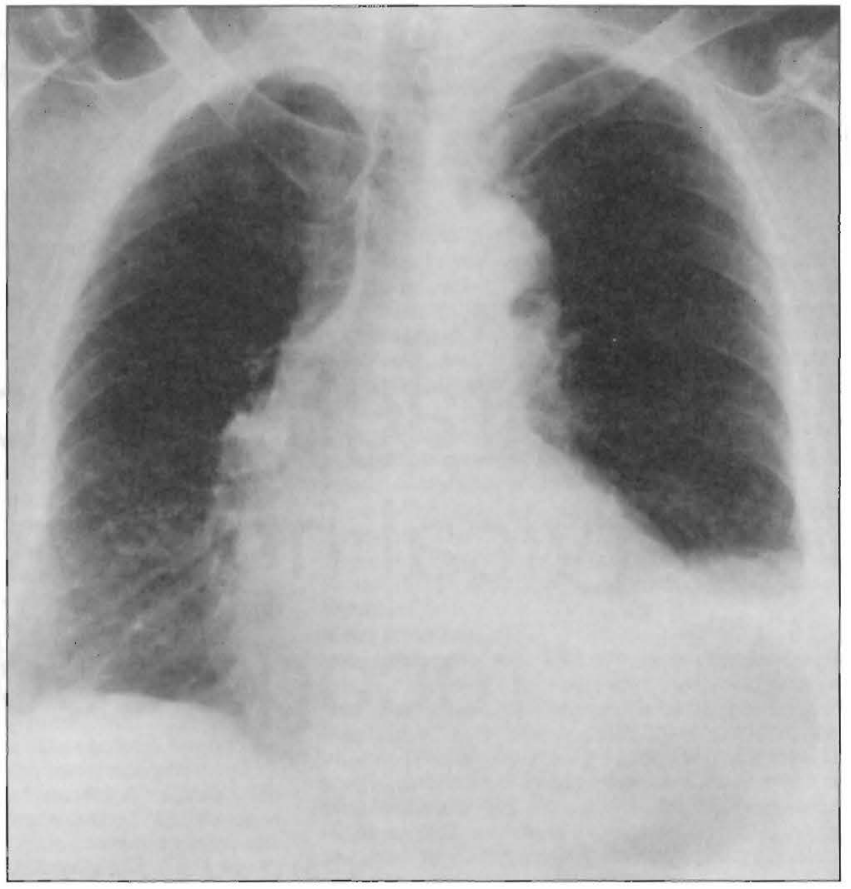

Figure 2) Chest radiograph of patiem on dew 20)

\section{DISCUSSION}

The diaphragmatic paralysis was believed to be due to phrenic nerve involvement by cervical herpes zoster for the following reasons: the diaphragm was radiographically normal the day before the rash appeared and the paralysis lollowed within just a few days; the association is anatomicatly correct, the nerve supply to the diaphragn being from the IIIrd, IVth and Vth cervical roots; and there wats no evidence to indicate other etiologies.

Case reports of diaphragmatic paralysis following cervicall zoster are rare. The great majority of these reports are to be found in English language publicalions (2-15). In these reports there was either no prior radiography showing a normal diaphragm, or the interval between radiographs showing a normal and later paralyzed diaphragm was long (seven weeks to 11 years). As well, in several reports, the paralyzed diaphragm was discovered months to years after the rash. Thus, given the many causes of diaphragmatic paralysis (16), its discovery after cervical herpes zoster could have been coincidental.

The present report documents the complete sequence of events - normal diaphragm, rash of zoster and paralyzed diaphragm - within 18 days. The short time frame and lack of evidence to indicate other etiologies makes cause and effect more likily.

Diaphragmatic paralysis following cervical herpes 10 ster is probably underrecognized because the paralysis may be asymptomatic (17) and may therefore not be looked for, and the association may be missed if the interval between appearance of rash and detection of paralysis is long. 


\section{REFERENCES}

1. Black LF, Hyatt RE. Maximal respiratory pressures: normal values and relationship to age and sex. Am Rev Respir Dis 1969;99:696-702.

2. Halpern SL, Covner AH. Motor manifestations of herpes zoster; report of a case of associated permanent pitralysis of phrenic nerve. Arch Intern Med 1949;84:907-16.

3. Parker GW, Ramos ED. Paralysis of the phrenic nerve following herpes zoster. JAMA 1962;180:408-10.

4. Beard H. Phrenic paralysis due to herpes zoster. Med Bull US Army - Europe. 1963;20:106.

5. Spiers AS. Herpes zoster and its motor lesions, with a report of a case of phrenic nerve paralysis. Med J Aust 1963;1:850-3.

6. Donald T. Paralysis of the diaphragm secondary to herpes zoster. J Med Assoc Ala 1964;33:306-8.

7. Brostoff J. Diaphragmatic paralysis after herpes zoster. BMJ 1966:2:1571-2.

8. Pratt-Johnson. Diaphragmatic paralysis after herpes. BMJ 1967;1:234-5

9. Anderson JP, Keal EE. Cervical herpes zoster and diaphragmatic paralysis. Br J Dis Chest 1969;63:222-6.

10. Shivalingappa G. Diaphragmatic paralysis following herpes zoster. Gerontol Clin 1970;12:283-7.

11. Dutt AK. Diaphragmatic paralysis caused by herpes zoster. Am Rev Respir Dis 1970;101:755-8.

12. Anderson JP. Paralysis in herpes zoster. BMJ 1970;3:587.

13. Devereaux L, Lacquet LM. Hemidiaphragmatic paralysis after cervical herpes zoster. Thorax 1982;37:870-1.

14. O'Doherty CJ, Savin JA. Dermittologic dyspnca. Int J Dermatol 1486;25:58-9.

15. Stowasser M, Cameron J, Oliver WA. Diaphragmatic paralysis following cervical herpes zoster. Med J Aust 1990;153:555-6.

16. Riley EA. Idiopathic diaphragmatic paralysis. A report of cight cases. Am J Med 1962:32:404-16.

17. Light RW. Diseases of the pleura, mediastinum, chest wall, and diaphragm. In: George RB, Light RW. Mathay MA, Matthay RA, eds. Chest Medicine - Essentials of PuImonary and Critical Care Medicine. Baltinore: Willians \& Wilkins [900:381-412.

\section{BOOKS}

New Therapies for Neonatal Respiratory Failure: a Physiological Approach, edited by Bruce R Boynton, Waldemar A Carlo and Alan H Jobe (1994). Cambridge University Press, 40 West 20th Street, New York, New York 10011-4211, USA. 357 pages; ISBN 0-521-43161-1; US\$110.00

This monograph on neonatal lung disease and therapy is really the compilation of the information for three distinct domains of perinatal pulmonary disorders that are only linked by the age group involved. The format of the chapters is especially useful in that having other disciples of the subject comment and critique a leading authority's observations on a subject allows rapid and concise identification of areas of agreement and discrepancy in a limited space. I found the overall presentation and discourse brief, delightful, complete with pithy yet insightful comments, and I think that this format of monograph is to be encouraged.

The first section of the monograph is related to 'Surfactant and its usage'. This section of approximately 100 pages, coordinated by Dr A Jobe, covers structure, function, metabolism of surfactant, as well as its clinical usage in respiratory distress syndrome and other neonatal diseases.

The second section of the monograph on mechanical ventilation is more extensive and occasionally repetitive. In part, this repetition was because the area of discussion was contentious, with more extensive commentary upon the narrative, and, in part, because the section encompasses all aspects of mechanical ventilation from physiology to different modalities. It is an extremely well-written, balanced approach to a common clinical problem but fails to emphasize that the new extrene ventilatory support measures are only necessary to a small proportion of patients.

However, the sections on the mechanics of breathing, pulmonary gas exchange and advances in conventional mechanical ventilation are excellent synoptic distillates of the current state of knowledge for the neonate. Moreover, the commentary is particularly apt in highlighting the areas of controversy for each chapter. I do helieve that these sections should be required reading for all medical personnel involved in the care of neonates and young infants. The latter sections on the more esoteric techniques of ventilation again are excellent distillates of the current state of knowledge, leavened by the insightful, practical comments about the use and limitations of these technicues.

The final three chapters on alternative methods of ventilation (negative pressure, continuous llow and liquid ventilation) constitute a summary of the current and probable future directions of research in this area. As summaries of the present state of knowledge, especially as applied to the newborn, these chapters are invaluable. There is extensive commentary throughout this section, highlighting the areas of controversy (and just plain lack of knowledge) with the overall impression summed up in the statement by Dr Chernick that "A lot of work will be required, but I, like the authors, remain cautiously optimistic about the new therapy."

The final section of the monograph is linited to two specific therapies - extracorporeal membrane oxygenation (ECMO) and nitric oxide. The chapter on the physiology of ECMO is a succinct explanation of the physiology and the different types of support available, many of which are only suitable for adult patients. The clinical chapter on the use and misuse of ECMO is well donc, with extensive commentary leading to a very balanced view and attempts to integrate the place of this therapy in light of the new treatment modalitics discussed in the last chapter. It is unfortunate that the section (n nitric oxide physiology in the lung does not reflect the general excellence of the rest of the text: undoubtedly this is a function of a review in a fast-developing area of medicine with new information available on at monthly basis.

In summary I found this compilation to be a well-balanced, well-written summary of the present state of knowledge. The format with the commentators is particularly valuable in delineating the areas of controversy while adding a degree of leavening to the text to render the material readable.

Michael Daris $M D$ The Montreal Children's Hospital Montral. Quebec 


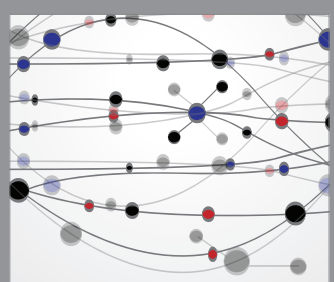

The Scientific World Journal


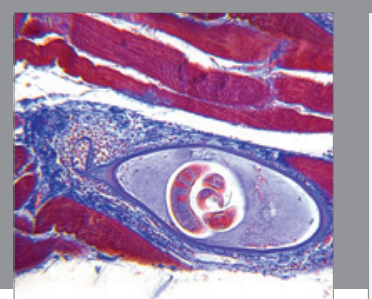

Gastroenterology Research and Practice



\section{Hindawi}

Submit your manuscripts at

http://www.hindawi.com
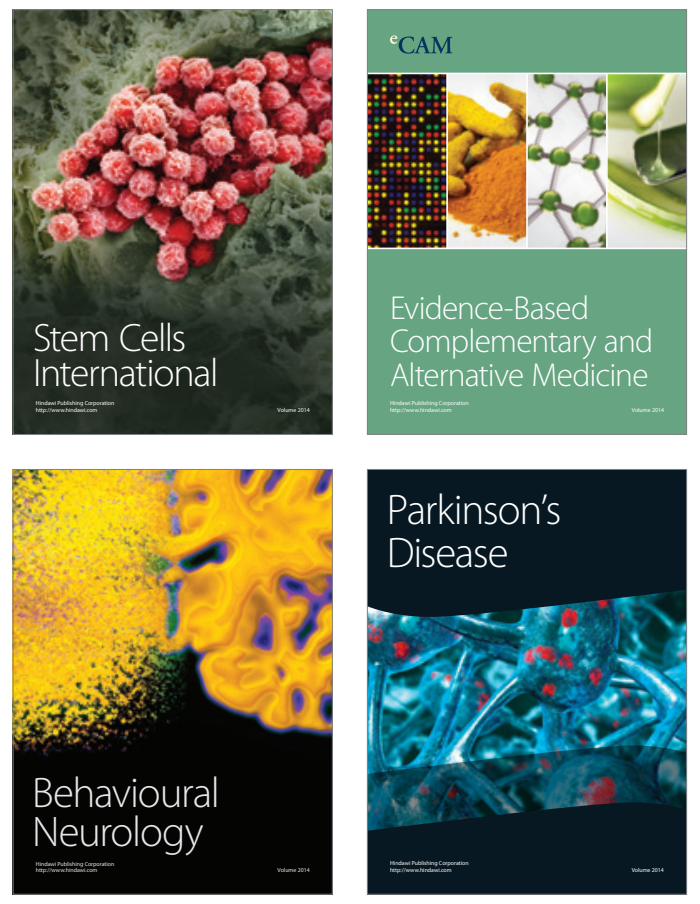
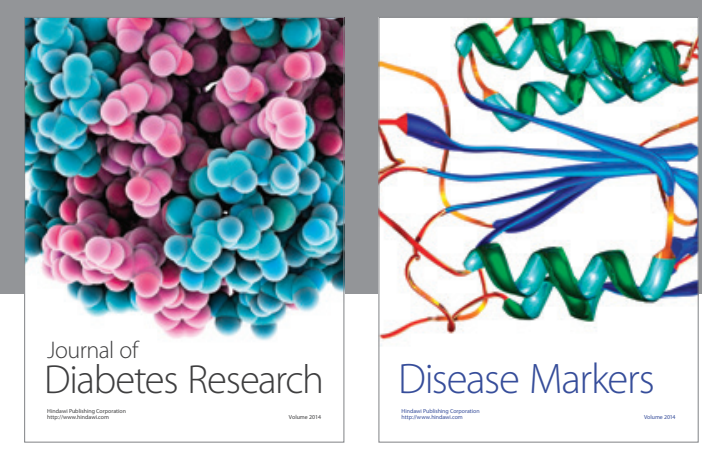

Disease Markers
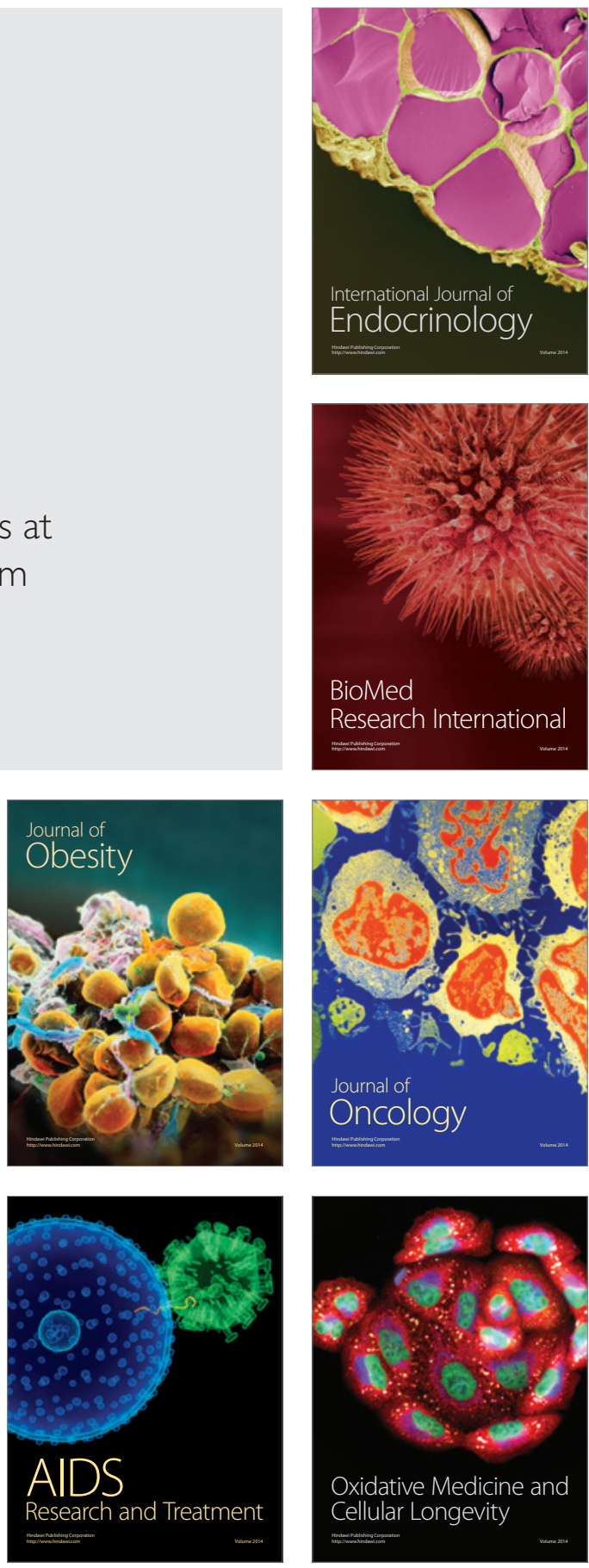